\title{
Ecological value of different vegetated strip types in providing valuable insect-rich habitats for grey partridge chicks
}

\author{
A. Volpato ${ }^{1 \dagger}$, J. Moran ${ }^{1}$ \\ ${ }^{1}$ Department of Natural Sciences, Galway-Mayo Institute of Technology, Galway, Ireland
}

Abstract

The intensification and specialisation of agriculture has contributed to farmland wildlife decline, including farmland birds. Grey partridge is a farmland species which has experienced a significant decline across Europe in recent decades. Chick survival rate is a key determinant of grey partridge population change and depends essentially on the availability of insect food. In this study, ground-dwelling and canopy-dwelling insects were collected using pitfall trapping and sweep netting methodologies, respectively, on different strip types in an area established for the conservation of grey partridge. The aim was to further our understanding of the value of different vegetated strip types in providing insect-rich habitats for grey partridge chicks. Overall, wildflower strip (WS) provided the greatest insect abundance. Significantly more ground-dwelling insects were found on WS, natural regeneration (NS) and leguminous strips (LS) than on grass strip (GS). Canopy-dwelling insects were also significantly more abundant on WS compared to all other strip types. This study highlights that WSs may represent important habitats in providing insect-rich food for grey partridge chicks and sowing these strips may therefore play a key role in decreasing chick mortality and supporting grey partridge conservation. It also demonstrates that other different vegetated strip types may still provide strip-specific insect taxa, in addition to other valuable resources. This study recommends a complex mosaic of different strip types to provide key resources for grey partridge, such as insect and plant food, nesting habitats and overwinter cover.

Keywords

Canopy-dwelling insects $\cdot$ chick insect food $\bullet$ grey partridge (Perdix perdix) $\bullet$ ground-dwelling insects $\bullet$ vegetated strips

\section{Introduction}

Agricultural production in Western Europe has experienced significant intensification over recent decades (Batáry et al., 2015). The intensification of agriculture based on increased agrochemical use, mechanisation and homogenisation of agricultural landscapes has led to the rapid decline in farmland wildlife across a wide range of taxa (Stoate et al., 2001; Benton et al., 2003; Kleijn \& Sutherland, 2003), including farmland birds (Siriwardena et al., 1998; Donald et al., 2001; Vickery et al., 2004; Gilbert et al., 2021) and their food sources such as insects (Vickery et al., 2001; Benton et al., 2002; Holland et al., 2006). The availability of insect food is an important factor influencing farmland birds (Vickery et al., 2001; Bowler et al., 2019), including grey partridge (Perdix perdix L.) (Benton et al., 2002; Holland et al., 2006).

The grey partridge is a farmland species and one of the most iconic game birds in Europe (Bro et al., 2004; Joannon et al., 2008; Aebischer \& Ewald, 2012). It is often described as an archetypal farmland bird closely linked with openfarmed landscapes (Potts, 1986) and sensitive to changes in farming practices and agricultural intensification (Sotherton et al., 2014). The grey partridge was a common bird species of agricultural landscapes across Europe but in the recent decades has shown dramatic declines (Tucker \& Heath, 1994; Birdlife International, 2004). Due to these steady and significant declines, the status of the European grey partridge population is now considered threatened with a decreasing breeding population (Article 12 European Assessment, available at https://nature-art12.eionet.europa.eu/article12/). In Ireland from the 1950s onwards, the grey partridge was sparsely distributed, while just a few decades later the native population consisted of less than 200 breeding pairs (Whilde \& Partridge, 1993). However, in those areas in which no releases from game farms had taken place, local extinction had already occurred years earlier (Buckley et al., 2012). At 
the beginning of the 1990s, a survey of the last two wild grey partridge populations was carried out in two cutaway peat land bogs at Boora (County Offaly) and Lullymore (County Kildare). In 1994, the Lullymore population comprised only 3 4 pairs, and by 2000 , grey partridge in this area were extinct (Buckley et al., 2012). In 1996, a joint conservation project was established in Boora with the aim of conserving and enhancing the last remaining wild grey partridge population in Ireland (Kavanagh et al., 2001; Egan, 2008; Buckley et al., 2012). Although the initial response of this recovery project was encouraging with a slight increase in the total autumn grey partridge population, due to bad weather conditions in the three successive summers and the loss of habitat for forestry and grassland, the population in Boora significantly declined to 22 individuals in autumn 2001 (Buckley et al., 2012).

In 2005, with the purchase of 250 ha of cutaway bog at Boora by National Parks and Wildlife Service (NPWS) from Bord na Móna, the initial conservation project further expanded with the establishment of the new NPWS Grey Partridge Project (NPWS GPP) in 2006. The NPWS GPP has had mixed success in terms of grey partridge numbers so far with an estimate of density between 25 and 30 pairs per 100 ha in spring 2020. However, current indications are that the population is not expanding into surrounding farmland areas (personal communication), confirming the findings reported in a report in 2017 that there were no grey partridge individuals outside the core NPWS GPP area and a low population within the project area (Kavanagh, 2017).

Despite numerous attempts to conserve the Irish grey partridge population, this farmland species has been included in the red list of birds of conservation concern (Colhoun \& Cummins, 2013; Gilbert et al., 2021), with an average population in Ireland between 106 and 116 pairs in 20182019 (Article 12 European Assessment tool, available at https://nature-art12.eionet.europa.eu/article12/). The grey partridge population decline is related to the intensification of agriculture and farming practices (Potts, 1986). Three main causes were identified: the increase in the predation pressure, especially during nesting which may result in both adult and nest losses; the destruction of nesting habitats due to the loss of ecological valuable agricultural areas, including farmland linear habitats such as species-rich field margins and vegetated strips; and the reduction of chick food insects due to the intensification of farming practices, such as the diffuse application of insecticides and herbicides which is associated with the reduction in chick survival through direct and indirect effects (Potts, 1986).

Grey partridge chick survival has been identified as a key determinant of population change, with annual chick survival rates explaining over two-thirds of the annual variation in the population index (Aebischer \& Ewald, 2012). Similarly, previous studies have highlighted that the population crash after 1950 in the UK and in other European countries is closely linked to chick survival (Potts, 1986). Average chick survival in the period $1903-1950$ was $51 \%$, while only a few years later it had dropped to less than 20\% (Potts \& Aebischer, 1995), remaining at a constant low level with an average of $33 \%$ from 1955 to 1993 (Kuijper et al., 2009).

Although grey partridge adults feed mainly on plant food, the chick diet during their first $2-3$ wk of life is composed predominantly of insects (Potts, 1986; Brewin et al., 2020). Preferred insect chick food includes among others, plant bugs (Hemiptera: Miridae), ground beetles (Coleoptera: Carabidae), weevils (Coleoptera: Curculionoidea), plant hoppers (Hemiptera: Fulgoromorpha), leaf beetles (Coleoptera: Chrysomelidae), ant pupae (Hymenoptera: Formicidae), sawfly larvae (Hymenoptera: Symphyta) and lepidopteran caterpillars (Lepidoptera) (Potts, 1986; Moreby et al., 2006). Research involving nutrition experiments indicated that high protein intake from insects is crucial for chick survival and development (Southwood \& Cross, 2002). Other studies have reported that chicks fed on an insectrich diet grew faster and were heavier than other chicks. Furthermore, their primaries developed earlier, while chicks fed on an insect-poor diet cooled faster resulting in greater mortality over time (Liukkonen-Anttila et al., 2002). There is therefore a close relationship between chick survival and insect abundance (Potts, 1986; Moreby et al., 2006; Aebischer \& Ewald, 2012).

The main factors which may cause a significant decrease in chick survival rate have shown to be related to the intensification of farming practices, including the widespread use of agrochemicals, such as insecticides and herbicides, and the loss and fragmentation of important chick-rearing habitats, such as vegetated strips and species-rich field margins (Kuijper et al., 2009; Aebischer \& Ewald, 2012). These ecologically enhanced habitats have shown to improve the availability of crucial foraging resources for both grey partridge chicks and adults, in addition to providing nesting sites (Buner et al., 2005; Brewin et al., 2020). Previous studies have shown that grey partridge quickly profit from these habitats with greater densities in these non-crop habitats in comparison to crop habitats and conventional agricultural fields (Bro et al., 2004; Buner et al., 2005).

In this study, the effects of five differently vegetated strips on insect density were investigated with the aim of understanding their role in providing valuable insect-rich habitats for grey partridge chicks. This study is important because the knowledge of insect occurrences in different vegetated strip types within agricultural areas and the factors influencing habitat selection and food availability may assist in maximising the value of foraging habitats for farmland birds such as grey 
partridge (Douglas et al., 2009). In particular, the objectives of this study were to:

(1) Compare the value of diverse strip types for insect assemblages, including grey partridge chick key prey items, with reference to ground- and canopy-dwelling insects

(2) Evaluate the effects of different strip types on Carabidae and Staphylinidae abundance within the ground-dwelling insect group

(3) Describe how different strip types affect the occurrences of the most abundant canopy-dwelling insect taxa, such as Diptera, Hemiptera, Coleoptera and Hymenoptera. By addressing these research questions, conservation measures for grey partridge can be more informed and effective

\section{Materials and methods}

\section{Study sites}

The study was carried out in Boora, County Offaly (Ireland). Most of the area was formerly described as a peatland, which has been harvested by the semi-state company Bord na Móna to produce energy, domestic fuel and horticulture peat (Kavanagh et al., 2001; Egan, 2008). The extraction of the peat resource in the area lasted for approximately $40 \mathrm{yr}$ leaving an open and impoverished area described as cutaway peat land (Buckley et al., 2012). Although initially the re-use of this site was focused on the development of grasslands and coniferous plantations, numerous large areas were not suitable for these land use options due to the soil characteristics, including drainage conditions. Therefore, in 1995, a group composed of representatives from Bord na Móna and local communities developed an integrated land use plan which included the natural recolonisation and development of a wide range of wetland and wildlife habitats (Egan, 2008). In 2006, the NPWS GPP further developed the area with the establishment on bare peat areas of a heterogeneous landscape characterised by cereal crops interspersed with different linear habitat types, including grass (GS) and wildflower strips (WS). These habitats were designed to provide the fundamental resources required by grey partridge such as seed-rich and insect-rich habitats and nesting cover (Kavanagh et al., 2001).

In this study, insect abundances were analysed between July and September 2019 in five different strip types: cereal strip (CS), GS, WS, natural regeneration strip (NS) and leguminous strip (LS). These strip types have been chosen to represent the main strip types present in the area of study. The CS and WS were established in 2018, LS in 2017, and GS was established in 2013. The NS was a grass field margin that has been set aside for a few years. Strips were sown with seed mixtures commercially available and were not sprayed with agrochemicals. All the strips were bounded by other linear features. The CS, WS, LS and NS were bounded by grassy field margins on one side and by greenways on the other. The GS was bounded by a green way and a WS. The most dominant plant species present in each strip type were assessed using direct visual assessment in three different $1-\mathrm{m}^{2}$ quadrats placed randomly in each strip. Strips dimensions did not vary considerably between the different strip types, with an average length between 50 and $75 \mathrm{~m}$ and an average width between 2 and $5 \mathrm{~m}$.

\section{Sampling protocol}

Ground-dwelling insects were sampled using pitfall traps. Pitfall trapping was carried out because it is the best-known cheap and easy sampling methodology for the capture of large samples of ground-dwelling insects, including Carabidae and Staphylinidae (Schmidt et al., 2006; Kotze et al., 2011). One group of six traps was set up in the centre of each strip type along a transect parallel to the strip margin in order to optimise the catch and minimise occasional trap losses (Kotze et al., 2011). Each trap within every trap group was placed at a distance of $10 \mathrm{~m}$ from each other. The minimum distance between each trap group was $200 \mathrm{~m}$ to allow sample independence. Plastic cups (depth: $10 \mathrm{~cm}$; diameter: $8.5 \mathrm{~cm}$ ) were situated just below the soil surface. Pitfall traps were half filled with $70 \%$ ethylene glycol and a few drops of unscented and uncoloured detergent to break the surface tension. Traps were covered to prevent flooding, desiccation, scavenging and by-catch (Lange et al., 2011). During the sampling period, the ethylene glycol was rarely diluted further by rainwater and no trap overflowed. Ground-dwelling insects were collected after $10 \mathrm{~d}$ in three sampling periods from July to September. All samples collected were kept in $70 \%$ ethylene glycol and taken to laboratory for further analysis. Carabid beetles were identified to species level using Luff (2007), while staphylinids were separated into morphospecies according to morphological characteristics using the protocol described by Oliver \& Beattie (1993). Rapid biodiversity evaluation methodologies such as those based on morphospecies have been widely and effectively used for the rapid identification of numerous and diverse insect groups that otherwise would have required time and specific expertise not readily available (Carey et al., 2017).

Canopy-dwelling insects were sampled by sweep netting the vegetation canopy. Sweep netting methodology was carried out because it has been preferentially used for the capture of chick food insects in previous studies (Itämies et al., 1996; Thomas et al., 2001). In each strip type, three $10 \mathrm{~m}$-transects parallel to the strip margin were walked at a slow speed and insects were collected using a standard sweep net of 0.4-m diameter with a $0.38-\mathrm{m}$ wooden handle and a net bag with a curved tip to prevent insects escaping. 
Each transect within the same strip type was at a distance of $10 \mathrm{~m}$ from each other. Strip types were randomly sampled in sunny and dry weather conditions twice on the same day (one in the morning and one in the afternoon) in two sampling periods from July to August. All insects captured were anaesthetised/killed using killing jars containing ethyl acetate and afterwards placed in sampling plastic bags and taken to the laboratory. All sampling bags were hand-sorted and all insects were removed and transferred to containers filled with $70 \%$ ethanol. Due to the large numbers and diversity of canopy-dwelling insects collected, all specimens were firstly sorted to order and afterwards separated into morphospecies. Although a very low number of the European honey bee (Apis mellifera L.) were captured, they were not included in the analysis because their occurrence largely depends on human factors such as hive management rather than merely ecological factors (Kremen et al., 2004; Winfree et al., 2007).

\section{Data analysis}

For statistical analyses, abundances of ground- and canopydwelling insects were treated separately. For both groundand canopy-dwelling insect groups, statistical analyses were carried out using the cumulative total number of specimens collected in each strip type. Similar procedure was used to calculate the abundance of all taxa collected, including Carabidae and Staphylinidae within the ground-dwelling insect group, and Diptera, Hemiptera, Hymenoptera and Coleoptera within the canopy-dwelling insect group. Statistical analyses of Lepidoptera, Orthoptera, Odonata and Diplura abundances within the canopy-dwelling group were not performed due to the low number of specimens of these taxa collected. Abundances of the two main insect groups and of all insect taxa collected did not display a Poisson distribution and were assessed using general linear mixed models with normal error distribution (West et al., 2014). Strip type was included as fixed factor in the models, while trap/transect identity was included as random factor. Where a significant effect of strip type was shown, post hoc Tukey tests were performed to determine significant differences between different strip types. For the analysis of the effects, significance was set at $P<0.05$. Before running general linear mixed models, normal distribution of all insect taxa/group abundance was tested. Where data were not normally distributed, In $(x+1)$ was used to transform the data and meet assumptions of normality. If data were not normally distributed even after $\ln (x+1)$ transformation, nonparametric Mann-Whitney $U$ tests were performed to test the effects of different strip types on insect abundances. Statistical analyses were carried out using the software SPSS v25 (IBM SPSS Statistics 2017, Armonk, NY, USA) for ground- and canopy-dwelling insect groups.

\section{Results}

The botanical assessment of the most dominant plant species carried out in each strip type found that CS was entirely dominated of cereal crop species (Triticum spp.), meanwhile GS was composed mainly of cocksfoot (Dactylis glomerata L.) and creeping red fescue (Festuca rubra L.). The WS was composed mostly of Daucus carota L., Ranunculus spp., Trifolium spp., Achillea millefolium L., Lotus corniculatus L. and Chrysanthemum leucanthemum Lam., interspersed with a few tussocky grass species consisting mainly of $D$. glomerata. The NS represented a transitional stage dominated almost completely of scrub species such as grey willow (Salix cinerea L.) and grass/herbaceous species such as $D$. glomerata, $F$. rubra and Epilobium angustifolium (L.) Scop. The LS was composed mostly of Medicago sativa L., Trifolium spp., Melilotus spp., Malva alcea L. and Cichorium intybus L.

In total, 6,852 insects were collected during the sampling period. The WS harboured greater abundance of insects with 2,966 specimens, followed by LS with 1,747 individuals, NS with 1,046 insects and GS with 610 specimens. The CS had less insects with just 483 individuals (Figure 1). A total of 46 species/morphospecies (1,356 individuals) of grounddwelling insects were captured using pitfall traps. The number of ground-dwelling specimens collected in the 10-d sampling period in each of the three collections ranged from a maximum of 597 individuals in the first collection (2 August), of which 224 were carabids and 373 were staphylinids, to a minimum of 291 individuals in the last collection (19 September), of which 201 were carabids and 90 were staphylinids. The list of Carabidae species collected in this study is reported in Appendix A1. Ground-dwelling insect abundance differed significantly among strip type $(P<0.001)$. Post hoc Tukey

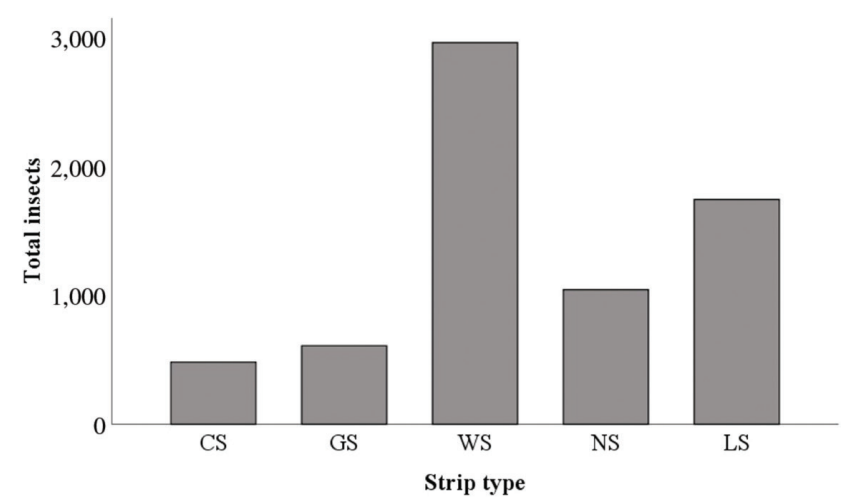

Figure 1. Number of total insects collected across each strip type (cereal strip [CS], grass strip [GS], wildflower strip [WS], natural regeneration strip [NS], leguminous strip [LS]) in Boora, Co. Offaly (Ireland) in 2019. 
tests showed significantly greater abundance on LS, NS and WS compared to GS. Although more ground-dwelling individuals were found on CS compared to those found on GS, there were no significant differences between these two strip types (Figure 2).

Analyses of Carabidae and Staphylinidae abundance showed different patterns for the two ground-dwelling insect groups. Within the family Carabidae, significantly greater abundance was found on NS, WS and LS compared to CS and GS. Among the family Staphylinidae, significantly more rove beetle specimens were found on LS and CS compared to NS and GS. Significantly greater staphylinid abundance was also found on LS compared to WS.

A total of 5,496 canopy-dwelling insects (121 morphospecies) were collected during the two sampling periods. The most abundant taxa were Diptera with 2,989 specimens separated into 40 morphospecies. Within the order Diptera, the most numerous individuals were small flies $(<5 \mathrm{~mm})$ belonging to the families Milichiidae, Periscelididae, Sciaridae, Sepsidae and Dolichopodidae. The second most abundant taxa were Hemiptera with 18 morphospecies and 1,764 specimens, of which the most abundant individuals were true bugs and plant hoppers belonging, respectively, to the suborders Heteroptera (family Miridae) and Homoptera (family Aphrophoridae). Hymenoptera were the third most abundant taxa with 468 individuals and 35 morphospecies followed in decreasing order by Coleoptera (252 individuals and 16 morphospecies, of which the most abundant specimens belonged to the family Curculionidae), Lepidoptera (17 specimens and 3 morphospecies), Orthoptera (4 individuals

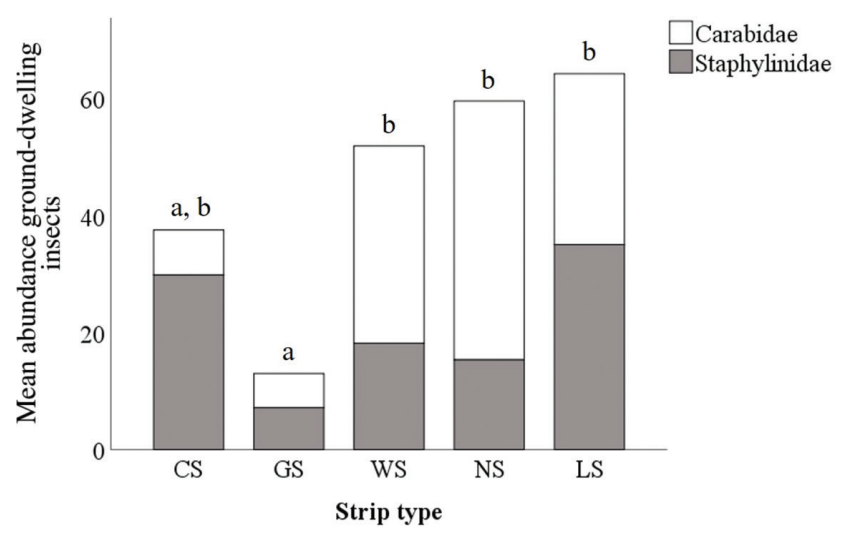

Figure 2. Overall mean abundance of ground-dwelling insects collected across each strip type (cereal strip [CS], grass strip [GS], wildflower strip [WS], natural regeneration strip [NS], leguminous strip [LS]), with reference to Carabidae and Staphylinidae. Different letters over the bars indicate significant differences among strip types $(P<0.05)$.

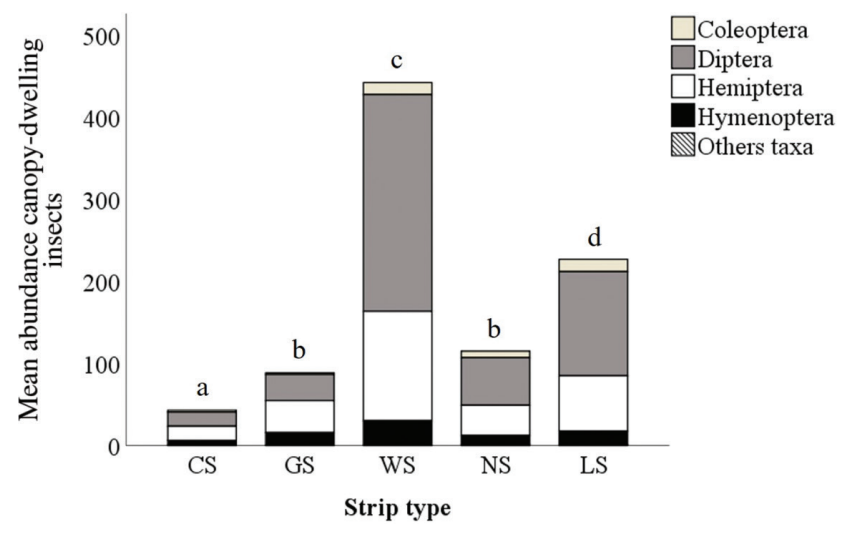

Figure 3. Overall mean abundance of canopy-dwelling insects collected across each strip type (cereal strip [CS], grass strip [GS], wildflower strip [WS], natural regeneration strip [NS], leguminous strip [LS]), with reference to the most abundant insect taxa (Coleoptera, Diptera, Hemiptera, Hymenoptera and Others taxa). Different letters over the bars indicate significant differences among strip types $(P<0.05)$.

and 2 morphospecies) and Odonata and Diplura (both with just one individual).

Canopy-dwelling insect abundance differed significantly among strip type $(P<0.001)$. Significantly greater abundance was found on WS compared to LS, NS, GS and CS. Significantly more specimens were also found on LS compared to NS, GS and CS. Furthermore, GS and NS contained significantly more canopy-dwelling insects compared to CS (Figure 3). Significantly more Diptera specimens were found on WS compared to NS, GS and CS. Significantly greater Diptera abundance was also found on LS and NS compared to CS, and on LS compared to GS. Among the order Hemiptera, significantly greater abundance was found on WS compared to all the other strip types, while CS had significantly less Hemiptera specimens. Within the group Hymenoptera, significantly greater abundance was found on WS compared to NS and CS, on LS compared to CS and on GS compared to CS. Among the order Coleoptera, the Mann-Whitney $U$ test found significantly more specimens on LS compared to NS, CS and GS, and on WS and NS compared to CS and GS.

\section{Discussion}

In this study, WS harboured more total insects than any other individual strip type. The beneficial influence of WSs on insect assemblages is supported by previous studies. These farmland linear habitats have been described as an effective and flexible tool to support insect occurrences in agricultural areas (Thomas \& Marshall, 1999). In a recent review, Haaland 
et al. (2011) reported that WSs tend to support greater insect abundance compared to other vegetated strip types. Greater insect abundances in these habitats are mainly due to factors such as plant diversity and flower abundance. Particularly, plant diversity is a key factor which may stimulate insect occurrences in differently vegetated strips, with beneficial effects on insect diversity (Marshall \& Moonen, 2002; Woodcock et al., 2005; Vickery et al., 2009). This is mainly due to the provision of a wide variety of valuable resources such as pollen, nectar, seeds and larval food in areas with a rich variety of flowering plants, which has positive effects for a wide range of insects (Marshall et al., 2006; Vickery et al., 2009). Flower abundance also plays an important role in supporting insect assemblages (Haaland et al., 2011). A greater number of flowering plants have shown to provide fundamental foraging resources for many insect species, including pollen and nectar feeders and predatory species (Zurbrügg \& Frank, 2006; Carvell et al., 2007). Another factor which may explain greater abundances on WS is the complex vegetation structure that characterises these linear habitats. The heterogeneous vegetation structure has shown to provide diverse niche for many species, thus promoting insect assemblages (Thomas \& Marshall, 1999; Aviron et al., 2006; Haaland et al., 2011).

It is therefore not surprising that in this study more insects were found on those strips with greater plant diversity and a more complex structure such as WS and LS, and to a lesser extent NS, while significantly lower insect abundance was found on those linear habitats such as GS and CS with lower plant species and structural complexity. These findings are supported by previous studies in which simple sward strips were compared to more complex and diverse sward strips. Thomas \& Marshall (1999) found greater arthropod abundances in wildflower plots compared to only grass plots. Similarly, Meek et al. (2002) reported a strong tendency for pollen and nectar-feeding insects, and to a lesser extent for predatory species, towards flower mixtures compared to tussocky grass mixtures. Other research found that species poor-vegetated strips resulted in lower abundances of pollinators, herbivores and predatory insects (Pywell et al., 2011). In our study, lower insect abundances on GS may therefore be due to the fact that this strip was sown with competitive grass species, including mainly cocksfoot $D$. glomerata, which may significantly reduce the sward species variety and structural complexity and consequently negatively influence insect occurrences. This is supported by previous research in which the less diverse sward has shown to support a lower diversity of broad-leaved forbs (Smith et al., 1997), thus providing fewer valuable habitats and resources for many species which may translate into significantly lower insect abundances (Vickery et al., 2002). As with GSs, CSs have shown in the literature to rarely sustain the diverse insect assemblages that generally occur in more botanically diverse strips (Vickery et al., 2009). Pywell et al. (2007) reported lower abundances of a wide range of insect taxa in cereal field margins compared to field margins sown with a flower mixture. This may be due to two main reasons: CSs are usually ploughed and sprayed with herbicides and insecticides, which are disruptive management practices for many insect species, and the vegetation is mainly composed of crop plants resulting in a less diverse habitat (Vickery et al., 2002).

A similar pattern to total insect abundances was found for ground-dwelling insects, with greater insect abundance on more complex sward strips compared to less diverse sward strips. Significantly more carabid beetles were found on NS, WS and LS compared to CS and GS. The beneficial effects of vegetated strips left to naturally regenerate on the occurrences of ground-dwelling insects such as carabid beetles have shown to be linked mainly to sward composition and structural heterogeneity (Vickery et al., 2009). In our study, most ground beetles collected on NS belonged to the single large body size species Pterostichus madidus Fabricius. Large body size and flightless carabid species are known to be associated with more stable and persistent habitats (Gnetti et al., 2015; Hiramatsu \& Usio, 2018), because in these less disturbed areas dispersal is less important (Riley \& Browne, 2011). However, grey partridge chicks seem to prefer smaller beetle species, such as those belonging to the genus Trechus and Bembidion, which have been reported to be key prey items in previous research (Potts, 1986; Moreby et al., 2006; Kuijper et al., 2009). In contrast to large body size carabid beetles, smaller species with flying capability have shown to be more closely linked to less stable habitats (Blake et al., 1994). This is because the rapid colonisation of more disturbed open habitats reflects their high dispersal capability (Riley \& Brown, 2011). It is not surprising therefore that in this study these small body size ground beetle species were more abundant on less stable habitats such as WS compared to more stable habitats such as NS, as supported by previous research (Meek et al., 2002). These findings may therefore suggest the importance of WSs in providing key ground beetle preys for grey partridge chicks.

Slightly different results were found for rove beetles, with significantly more staphylinids on LS and CS. If high abundance on LS may be explained by the complex structure and greater plant diversity, large number of staphylinids on CS may be due to the absence of agrochemical applications in this linear habitat. These results are supported by previous research in which the absence of agrochemicals has reported to favour specific ground-dwelling insect taxa (Moreby \& Southway, 1999). Furthermore, the extensification of agricultural practices on CSs, such as the strict restriction of agrochemical use, has shown to significantly increase the annual plant diversity (Critchley et al., 2004), providing 
valuable habitats for specific ground-dwelling insect species (Pywell et al., 2007).

Significantly greater canopy-dwelling insect abundances were found on WS compared to the other differently vegetated strips, suggesting the importance of these strips in providing many valuable resources for a wide range of canopy-dwelling insect taxa. Similar pattern was found for insects belonging to the order Diptera with greater insect abundance on WS. In this study, the majority of dipteran insects collected were very small morphospecies $(<5 \mathrm{~mm})$, which may have relatively poor value as dietary item for grey partridge chicks. This is because grey partridge chicks seem to prefer relatively larger insects, including bigger taxa within the Diptera such as crane flies (Tipulidae) (Potts, 1986). However, very few large-size species were found, suggesting the lesser importance of WSs in providing summer dipteran dietary items for grey partridge chicks.

Significantly greater abundance of Hemiptera was also found on WS compared to any other individual strip type. This is supported by previous studies in which WSs have shown to positively influence true bugs (Heteroptera) (Haaland et al., 2011). Key factors such as plant diversity, flower abundance and highly structured vegetation seem to play an important role in enhancing bug occurrences and predicting the presence of specific Heteroptera taxa (Frank \& Künzle, 2006; Zurbrügg \& Frank, 2006). These factors may explain the findings in this study in which WS seems to provide a valuable habitat for a wide range of Hemiptera taxa, including plant bugs and plant hopper, which are both known as key prey items and preferred insect food for grey partridge chicks (Potts, 1986; Itämies et al., 1996; Moreby et al., 2006). The WSs may therefore represent valuable habitats in providing key hemipteran prey for grey partridge chicks.

More Hymenoptera insects were also found on WS, confirming previous research in which wildflower areas provided important habitats for these insect taxa, especially larger species such as those belonging to the family Apidae (Haaland et al., 2011). However, in our study, most of the hymenopterans collected were very small parasitoid wasps. High abundance of parasitoid wasps on WS may be due to the fact that individuals of this wide hymenopteran group in the early stage of their life before ovipositing need a certain amount of energy obtained from flower nectar (Hatt et al., 2018), and areas with high concentrations of flowers such as WSs seem to represent the best habitats in providing more valuable food resources. However, previous studies indicated that other Hymenoptera taxa are preferred grey partridge chick food, such as sawfly (larvae) and ants (pupae) (Potts, 1986; Itämies et al., 1996; Moreby et al., 2006), which were not abundant in our study. Thus, as with Diptera, WSs may represent less important habitats in providing preferred hymenopteran preys for grey partridge chicks.
Greater abundance of canopy-dwelling Coleoptera was found on LS and WS. Pywell et al. (2007) found similar results, with more canopy-dwelling beetles in pollen and nectar mixture field margins compared to other differently vegetated margins, with the exclusion of WSs. Similarly, Meek et al. (2002) found more beetles collected with sweep netting in field margins sown with flower mixture. In another study, more herbivorous insects collected by sweep netting, including specimens of Coleoptera, were more abundant on wildflower plots compared to other vegetated plot types (Pywell et al., 2011). Most of the canopy-dwelling beetles collected in our study were herbivorous such as leaf beetles and weevil. These groups have been regarded as important grey partridge chick food components (Potts, 1986; Itämies et al., 1996; Moreby et al., 2006), suggesting therefore the importance of areas sown with flower mixture such as LS and WS in providing valuable Coleoptera prey for grey partridge chicks.

Although the results of this research showed quite clearly the importance of complex sward strips with higher plant diversity and flower abundance, such as WS, in providing valuable habitats for many grey partridge chick insect preys, this was a small-scale initial study. Due to the limited amount of resources available, it was impossible to enhance the number of replicates including more than one strip per type in the analysis, in addition to extending the sampling period from late spring to the beginning of autumn. A more complete and extended sampling protocol would have led to more robust results with a clearer and broader idea of the ecological value of different vegetated strip types. However, despite limited resources, this initial study has provided important preliminary results and new insights concerning the knowledge of the quite unique context of the area under study, in which original peat bogs and wetlands were cutover and then reclaimed for agricultural purposes.

\section{Conclusion}

Chick survival rate is a key factor determining grey partridge populations within agricultural areas and depends crucially on the availability of insect food. This study demonstrates that WSs may represent valuable habitats in providing insect-rich food for grey partridge chicks, including key prey items. Sown WSs may therefore contribute to decrease chick mortality and support targeted grey partridge conservation projects (Buner et al., 2005).

Although other vegetated strip types seem to be less valuable habitats in terms of insect prey abundance, this study shows that they may still provide valuable strip-specific insect taxa. A diversity of strip types is therefore ideally required to provide the optimum food supply for grey partridge chicks, in addition to other important resources for adults such as nesting habitats, 
brood-rearing and overwinter cover and food (Thomas et al., 2001; Henderson et al., 2004).

However, previous studies showed that these strips may act as ecological traps for grey partridge (Kuijper et al., 2009), acting as movement corridors for predators which may pose a serious threat (Josefsson et al., 2013). Therefore, it may be of greater value to place a range of different vegetated plot types adjacent to grey partridge nesting sites, including in the first place wildflower mixture, thus reducing the risk of predation (Holland et al., 2014).

To conclude, although there is no a one-size-fits-all solution to arrange an ideal grey partridge landscape, a heterogeneous mosaic of cereal crops interspersed with different vegetated strips and plots may therefore represent a key landscape configuration for the conservation of grey partridge populations within agricultural areas.

\section{Acknowledgements}

We wish to thank the National Parks and Wildlife Service Grey Partridge Project (NPWS GPP), the NPWS North-East Regional Manager Padraig O'Donnell, Noel Bugler, Colm Malone and NPWS Regional Staff and the Department of Housing, Local Government and Heritage for their support throughout the whole duration of this study in providing key management information and funding. We also wish to thank Michael Martyn (Martyn Agri-environment Consultant) for providing details on the establishment and management of the vegetated strips. A special thanks goes to Darren Haslam (NPWS GPP Head Game Keeper) for facilitating access to the study site. We also thank Mairead Duffy and Saidhbh Mc Intyre for assisting during the fieldwork and helping with species/morphospecies identification in the laboratory.

\section{References}

Aebischer, N.J. and Ewald, J.A. 2012. The grey partridge in the UK: population status, research, policy and prospects. Animal Biodiversity and Conservation 35: 353-362.

Aviron, S., Herzog, F., Klaus, I., Luka, H., Schupbach, L.P.B. and Jeanneret, P. 2006. Effects of Swiss agri-environmental measures on arthropod biodiversity in arable landscapes. Aspects of Applied Biology 81: 101.

Batáry, P., Dicks, L.V., Kleijn, D. and Sutherland, W.J. 2015. The role of agri-environment schemes in conservation and environmental management. Conservation Biology 29: 1006-1016.

Benton, T.G., Bryant, D.M., Cole, L. and Crick, H.Q. 2002. Linking agricultural practice to insect and bird populations: a historical study over three decades. Journal of Applied Ecology 39: 673-687.
Benton, T.G., Vickery, J.A. and Wilson, J.D. 2003. Farmland biodiversity: is habitat heterogeneity the key?. Trends in Ecology \& Evolution 18: 182-188.

Birdlife International. 2004. "Birds in Europe: Population Estimates, Trends and Conservation Status". BirdLife International, Cambridge.

Blake, S., Foster, G.N., Eyre, M.D. and Luff, M.L. 1994. Effects of habitat type and grassland management practices on the body size distribution of carabid beetles. Pedobiologia 38: 502-512.

Bowler, D.E., Heldbjerg, H., Fox, A.D., de Jong, M. and BöhningGaese, K. 2019. Long-term declines of European insectivorous bird populations and potential causes. Conservation Biology 33: 1120-1130.

Brewin, J., Buner, F. and Ewald, J. 2020. "Farming with Nature Promoting Biodiversity Across Europe Through Partridge Conservation". The Game \& Wildlife Conservation Trust, Fordingbridge, UK.

Bro, E., Mayot, P., Corda, E.V.E. and Reitz, F. 2004. Impact of habitat management on grey partridge populations: assessing wildlife cover using a multisite $\mathrm{BACl}$ experiment. Journal of Applied Ecology 41: 846-857.

Buckley, K., Kelly, P., Kavanagh, B.P., O'Gorman, E.C., Carnus, T. and McMahon, B.J. 2012. Every partridge counts, successful techniques used in the captive conservation breeding programme for wild grey partridge in Ireland. Animal Biodiversity and Conservation 35: 387-393.

Buner, F., Jenny, M., Zbinden, N. and Naef-Daenzer, B. 2005. Ecologically enhanced areas - a key habitat structure for reintroduced grey partridges Perdix perdix. Biological Conservation 124: 373-381.

Carey, J.G., Brien, S., Williams, C.D. and Gormally, M.J. 2017. Indicators of Diptera diversity in wet grassland habitats are influenced by environmental variability, scale of observation, and habitat type. Ecological Indicators 82: 495-504.

Carvell, C., Meek, W.R., Pywell, R.F., Goulson, D. and Nowakowski, M. 2007. Comparing the efficacy of agri-environment schemes to enhance bumble bee abundance and diversity on arable field margins. Journal of Applied Ecology 44: 29-40.

Colhoun, K. and Cummins, S. 2013. Birds of conservation concern in Ireland. Irish Birds 9: 523-544.

Critchley, C.N.R., Allen, D.S., Fowbert, J.A., Mole, A.C. and Gundrey, A.L. 2004. Habitat establishment on arable land: assessment of an agri-environment scheme in England, UK. Biological Conservation 119: 429-442.

Donald, P.F., Green, R.E. and Heath, M.F. 2001. Agricultural intensification and the collapse of Europe's farmland bird populations. Proceedings of the Royal Society of London. Series B: Biological Sciences 268: 25-29.

Douglas, D.J., Vickery, J.A. and Benton, T.G. 2009. Improving the value of field margins as foraging habitat for farmland birds. Journal of Applied Ecology 46: 353-362.

Egan, T. 2008. "The Lough Boora Parklands Project on Cutaway Bogland in West Offaly Ireland: Regional Ecological, Economic and Social Benefits". Peatland After-Use, 390-393. 
Frank, T. and Künzle, I. 2006. Effect of early succession in wildflower areas on bug assemblages (Insecta: Heteroptera). European Journal of Entomology 103: 61-70.

Gilbert, G., Stanbury, A. and Lewis, L. 2021. Birds of conservation concern in Ireland 4: 2020-2026. Irish Birds 43: 1-22.

Gnetti, V., Bombi, P., Taglianti, A.V., Bologna, M.A., D’andrea, E., Cammarano, M., Bascietto, M., De Cinti, B. and Matteucci, G. 2015. Temporal dynamic of a ground beetle community of Eastern Alps (Coleoptera Carabidae). Bulletin of Insectology 68: 299-309.

Haaland, C., Naisbit, R.E. and Bersier, L.F. 2011. Sown wildflower strips for insect conservation: a review. Insect Conservation and Diversity 4: 60-80.

Hatt, S., Uyttenbroeck, R., Lopes, T., Chen, J.L., Piqueray, J., Monty, A. and Francis, F. 2018. Effect of flower traits and hosts on the abundance of parasitoids in perennial multiple species wildflower strips sown within oilseed rape (Brassica napus) crops. ArthropodPlant Interactions 12: 787-797.

Henderson, I.G., Vickery, J.A. and Carter, N. 2004. The use of winter bird crops by farmland birds in lowland England. Biological Conservation 118: 21-32.

Hiramatsu, S. and Usio, N., 2018. Assemblage characteristics and habitat specificity of carabid beetles in a Japanese alpinesubalpine zone. Psyche: A Journal of Entomology 2018: 1-15.

Holland, J.M., Hutchison, M.A.S., Smith, B. and Aebischer, N.J. 2006. A review of invertebrates and seed-bearing plants as food for farmland birds in Europe. Annals of Applied Biology 148: 49-71.

Holland, J.M., Storkey, J., Lutman, P.J.W., Birkett, T.C., Simper, J. and Aebischer, N.J. 2014. Utilisation of agri-environment scheme habitats to enhance invertebrate ecosystem service providers. Agriculture, Ecosystems \& Environment 183: 103-109.

Itämies, J., Putaala, A., Pirinen, M. and Hissa, R. 1996. The food composition of grey partridge chicks Perdix perdix in central Finland. Ornis Fennica 73: 27-34.

Joannon, A., Bro, E., Thenail, C. and Baudry, J. 2008. Crop patterns and habitat preferences of the grey partridge farmland bird. Agronomy for Sustainable Development 28: 379-387.

Josefsson, J., Berg, A., Hiron, M., Pärt, T. and Eggers, S. 2013. Grass buffer strips benefit invertebrate and breeding skylark numbers in a heterogeneous agricultural landscape. Agriculture, Ecosystems \& Environment 181: 101-107.

Kavanagh, B.P. 2017. "Boore, Co. Offaly Grey Partridge Autumn Survey and Data Analysis, Report 2017 to The National Parks and Wildlife Service". Biology Division, Royal College of Surgeons in Ireland, 123 St Stephen's Green, Dublin 2.

Kavanagh, B.P., O'Gorman, C. and Buckley, C. 2001. The Irish grey partridge conservation strategy: an update 1995-1998. Hungarian Small Game Bulletin 6: 79-86.

Kleijn, D. and Sutherland, W.J. 2003. How effective are European agrienvironment schemes in conserving and promoting biodiversity? Journal of Applied Ecology 40: 947-969.
Kotze, D.J., Brandmayr, P., Casale, A., Dauffy-Richard, E., Dekoninck, W., Koivula, M.J., Lövei, G.L., Mossakowski, D., Noordijk, J., Paarmann, W. and Pizzolotto, R. 2011. Forty years of carabid beetle research in Europe-from taxonomy, biology, ecology and population studies to bioindication, habitat assessment and conservation. ZooKeys 100: 55-148.

Kremen, C., Williams, N.M., Bugg, R.L., Fay, J.P. and Thorp, R.W. 2004. The area requirements of an ecosystem service: crop pollination by native bee communities in California. Ecology Letters 7: 1109-1119. Kuijper, D.P.J., Oosterveld, E. and Wymenga, E. 2009. Decline and potential recovery of the European grey partridge (Perdix perdix) population-a review. European Journal of Wildlife Research 55: 455-463.

Lange, M., Gossner, M.M. and Weisser, W.W. 2011. Effect of pitfall trap type and diameter on vertebrate by-catches and ground beetle (Coleoptera: Carabidae) and spider (Araneae) sampling. Methods in Ecology and Evolution 2: 185-190.

Liukkonen-Anttila, T., Putaala, A. and Hissa, R. 2002. Feeding of hand-reared grey partridge Perdix perdix chicks - importance of invertebrates. Wildlife Biology 8: 11-19.

Luff, M.L. 2007. "The Carabidae (ground beetles) of Britain and Ireland". RES Handbook Volume 4, Part. 2. (2nd edition), Field Studies Council, Shrewsbury.

Marshall, E.J.P. and Moonen, A.C. 2002. Field margins in northern Europe: their functions and interactions with agriculture. Agriculture, Ecosystems \& Environment 89: 5-21.

Marshall, E.J.P., West, T.M. and Kleijn, D. 2006. Impacts of an agrienvironment field margin prescription on the flora and fauna of arable farmland in different landscapes. Agriculture, Ecosystems \& Environment 113: 36-44.

Meek, B., Loxton, D., Sparks, T., Pywell, R., Pickett, H. and Nowakowski, M. 2002. The effect of arable field margin composition on invertebrate biodiversity. Biological Conservation 106: 259-271.

Moreby, S.J. and Southway, S.E. 1999. Influence of autumn applied herbicides on summer and autumn food available to birds in winter wheat fields in southern England. Agriculture, Ecosystems \& Environment 72: 285-297.

Moreby, S.J., Aebischer, N.J. and Southway, S. 2006. Food preferences of grey partridge chicks, Perdix perdix, in relation to size, colour and movement of insect prey. Animal Behaviour 71: 871-878.

Oliver, I. and Beattie, A.J. 1993. A possible method for the rapid assessment of biodiversity. Conservation Biology 7: 562-568.

Potts, G.R. 1986. "The Partridge: Pesticides, Predation and Conservation”. Collins, London.

Potts, G.R. and Aebischer, N.J. 1995. Population dynamics of the grey partridge Perdix perdix 1793-1993: monitoring, modelling and management. Ibis 137: 29-37.

Pywell, R.F., Meek, W.R., Carvell, C., Hulmes, L. and Nowakowski, M. 2007. The Buzz project: biodiversity enhancement on arable land under the new agri-environment schemes. Aspects of Applied Biology 8: 61-68. 
Pywell, R.F., Meek, W.R., Loxton, R.G., Nowakowski, M., Carvell, C. and Woodcock, B.A. 2011. Ecological restoration on farmland can drive beneficial functional responses in plant and invertebrate communities. Agriculture, Ecosystems \& Environment 140: 62-67.

Riley, K.N. and Browne, R.A. 2011. Changes in ground beetle diversity and community composition in age structured forests (Coleoptera, Carabidae). ZooKeys 147: 601-621.

Schmidt, M.H., Clough, Y., Schulz, W., Westphalen, A. and Tscharntke, T. 2006. Capture efficiency and preservation attributes of different fluids in pitfall traps. The Journal of Arachnology 34: 159-162.

Siriwardena, G.M., Baillie, S.R., Buckland, S.T., Fewster, R.M., Marchant, J.H. and Wilson, J.D. 1998. Trends in the abundance of farmland birds: a quantitative comparison of smoothed Common Birds Census indices. Journal of Applied Ecology 35: 24-43.

Smith, H., Mcallum, K. and MacDonald, D.W. 1997. Experimental comparison of the nature conservation value, productivity and ease of management of a conventional and a more species-rich grass ley. Journal of Applied Ecology 34: 53-64.

Sotherton, N.W., Aebischer, N.J. and Ewald, J.A. 2014. Research into action: grey partridge conservation as a case study. Journal of Applied Ecology 51: 1-5.

Southwood, T.R.E. and Cross, D.J. 2002. Food requirements of grey partridge Perdix perdix chicks. Wildlife Biology 8: 175-183.

Stoate, C., Boatman, N.D., Borralho, R.J., Carvalho, C.R., De Snoo, G.R. and Eden, P. 2001. Ecological impacts of arable intensification in Europe. Journal of Environmental Management 63: 337-365.

Thomas, C.F.G. and Marshall, E.J.P. 1999. Arthropod abundance and diversity in differently vegetated margins of arable fields. Agriculture, Ecosystems \& Environment 72: 131-144.

Thomas, S.R., Goulson, D. and Holland, J.M. 2001. Resource provision for farmland gamebirds: the value of beetle banks. Annals of Applied Biology 139: 111-118.
Tucker, G.M. and Heath, M.F. 1994. "Birds in Europe, Their Conservation Status." Birdlife conservation series no. 3. Birdlife International, Cambridge.

Vickery, J.A., Bradbury, R.B., Henderson, I.G., Eaton, M.A. and Grice, P.V. 2004. The role of agri-environment schemes and farm management practices in reversing the decline of farmland birds in England. Biological Conservation 119: 19-39.

Vickery, J., Carter, N. and Fuller, R.J. 2002. The potential value of managed cereal field margins as foraging habitats for farmland birds in the UK. Agriculture, Ecosystems \& Environment 89: 41-52.

Vickery, J.A., Feber, R.E. and Fuller, R.J. 2009. Arable field margins managed for biodiversity conservation: a review of food resource provision for farmland birds. Agriculture, Ecosystems \& Environment 133: 1-13.

Vickery, J.A., Tallowin, J.R., Feber, R.E., Asteraki, E.J., Atkinson, P.W., Fuller, R.J. and Brown, V.K. 2001. The management of lowland neutral grasslands in Britain: effects of agricultural practices on birds and their food resources. Journal of Applied Ecology 38: 647-664.

West, B.T., Welch, K.B. and Galecki, A.T. 2014. "Linear Mixed Models: A Practical Guide Using Statistical Software". Second Edition, CRC Press, University of Michigan, Ann Arbor, USA.

Whilde, A. and Partridge, J.K. 1993. "Threatened Mammals, Birds, Amphibians and Fish in Ireland: Irish Red Data Book 2: Vertebrates". HM Stationery Office, Belfast.

Winfree, R., Griswold, T. and Kremen, C. 2007. Effect of human disturbance on bee communities in a forested ecosystem. Conservation Biology 21: 213-223.

Woodcock, B.A., Westbury, D.B., Potts, S.G., Harris, S.J. and Brown, V.K. 2005. Establishing field margins to promote beetle conservation in arable farms. Agriculture, Ecosystems \& Environment 107: 255-266.

Zurbrügg, C. and Frank, T. 2006. Factors influencing bug diversity (Insecta: Heteroptera) in semi-natural habitats. Biodiversity \& Conservation 15: 275-294. 
Appendix A1: List of Carabidae species collected during this investigation in 2019 in Boora, Co. Offaly (Ireland)

\begin{tabular}{|c|c|c|}
\hline Carabidae species list & $\begin{array}{c}\text { Overall } \\
\text { abundance }\end{array}$ & $\begin{array}{c}\text { Percentage } \\
\text { of total } \\
\text { abundance (\%) }\end{array}$ \\
\hline Agonum thoreyi Dejean & 5 & 0.69 \\
\hline Agonum emarginatum Gyllenhal & 1 & 0.14 \\
\hline Amara apricaria Paykull & 3 & 0.41 \\
\hline Amara aenea De Geer & 1 & 0.14 \\
\hline Amara bifrons Gyllenhal & 2 & 0.28 \\
\hline Amara eurynota Panzer & 36 & 4.98 \\
\hline Amara fulva Müller & 1 & 0.14 \\
\hline Amara lunicollis Schioedte & 6 & 0.83 \\
\hline Amara ovata Fabricius & 2 & 0.28 \\
\hline Anchomenus dorsalis Pontoppidan & 20 & 2.77 \\
\hline Bembidion lampros Herbst & 56 & 7.75 \\
\hline Blemus discus Fabricius & 3 & 0.41 \\
\hline Bradycellus harpalinus Serville & 1 & 0.14 \\
\hline Bradycellus verbasci Duftschmid & 8 & 1.11 \\
\hline Clivina fossor Linnaeus & 2 & 0.28 \\
\hline Curtonotus aulicus Panzer & 3 & 0.41 \\
\hline Harpalus latus Linnaeus & 1 & 0.14 \\
\hline Harpalus rufipes Degeer & 29 & 4.01 \\
\hline Nebria brevicollis Fabricius & 5 & 0.69 \\
\hline Oxypselaphus obscurus Herbst & 1 & 0.14 \\
\hline Patrobus assimilis Chaudoir & 1 & 0.14 \\
\hline Poecilus versicolor Sturm & 212 & 29.32 \\
\hline Pterostichus madidus Fabricius & 141 & 19.50 \\
\hline Pterostichus melanarius Illiger & 1 & 0.14 \\
\hline Synuchus vivalis Illiger & 3 & 0.41 \\
\hline Trechoblemus micros Herbst & 1 & 0.14 \\
\hline Trechus quadristriatus Schrank & 178 & 24.62 \\
\hline
\end{tabular}

